\title{
Nitric oxide regulates angiotensin-I converting enzyme under static conditions but not under shear stress
}

\footnotetext{
C.M. Pertrini ${ }^{*}$

A.A. Miyakawa ${ }^{1 *}$,

F.R.M. Laurindo ${ }^{2}$

and J.E. Krieger ${ }^{1}$
}

\author{
'Laboratório de Genética e Cardiologia Molecular, and \\ 'Laboratório de Biologia Vascular, Instituto do Coração (InCor), \\ Faculdade de Medicina, Universidade de São Paulo, \\ São Paulo, SP, Brasil
}

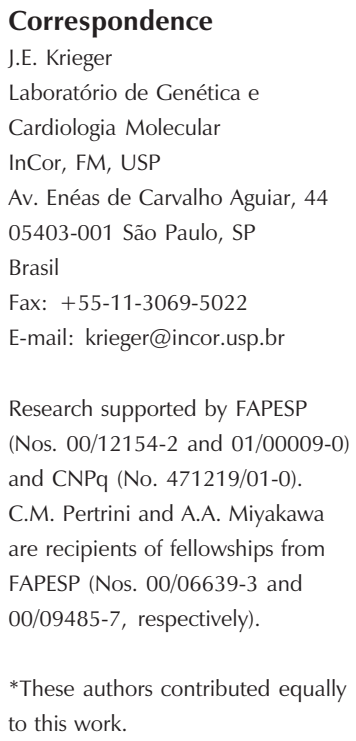

Received November 18, 2002 Accepted July 4, 2003

\begin{abstract}
Mechanical forces including pressure and shear stress play an important role in vascular homeostasis via the control of the production and release of a variety of vasoactive factors. An increase in vascular shear stress is accompanied by nitric oxide (NO) release and NO synthase activation. Previously, we have demonstrated that shear stress induces angiotensin-I converting enzyme (ACE) down-regulation in vivo and in vitro. In the present study, we determined whether NO participates in the shear stress-induced ACE suppression response. Rabbit aortic endothelial cells were evaluated using the NO synthase inhibitor LNAME, and two NO donors, diethylamine NONOate (DEA/NO) and sodium nitroprusside (SNP). Under static conditions, incubation of endothelial cells with $1 \mathrm{mM}$ L-NAME for $18 \mathrm{~h}$ increased ACE activity by $27 \%$ (from $1.000 \pm 0.090$ to $1.272 \pm 0.182$ ) while DEA/NO and SNP $(0.1,0.5$ and $1 \mathrm{mM})$ caused no change in ACE activity. Interestingly, ACE activity was down-regulated similarly in the presence or absence of L-NAME $\left(\Delta_{(0 \mathrm{mM})}=0.26 \pm 0.055, \Delta_{(0.1 \mathrm{mM})}=0.21 \pm 0.22\right.$, $\Delta_{(1 \mathrm{mM})}=0.36 \pm 0.13$ ) upon $18 \mathrm{~h}$ shear stress activation (from static to $15 \mathrm{dyn} / \mathrm{cm}^{2}$ ). Taken together, these results indicate that NO can participate in the maintenance of basal ACE levels in the static condition but NO is not associated with the shear stress-induced inactivation of ACE.
\end{abstract}

Shear stress is a tangential force acting on endothelial cells resulting from the contact between blood and the vascular wall. Endothelial cells respond to shear stress by altering the production of a variety of vasoactive factors, releasing nitric oxide (NO) (1) and prostacyclin (2), and inhibiting endothelin-1 (3). Shear forces also modulate the production of growth factors such as plateletderived growth factor (PDGF) (4) and fibroblast growth factor (FGF) (5).
Key words - Shear stress

- Angiotensin-I converting enzyme

- Nitric oxide

- Endothelial cells

....................
Laminar flow induces a biphasic NO production response with a burst of NO release at the onset of the stimulus, which is reduced after $30 \mathrm{~min}$ and then tonically maintained for the duration of the stimulus $(6,7)$. NO has been reported to modulate the control of expression of several genes such as monocyte chemotactic protein-1 (MCP-1) (8), vascular cell adhesion molecule-1, and intercellular adhesion molecule-1 (9). In addition, it has been demonstrated that NO regulates 
shear stress-induced changes in PDGF-A and MCP-1 gene expression (10).

We have demonstrated that shear stress decreases angiotensin-I converting enzyme (ACE) activity and expression in vitro and in vivo (11). There is evidence that NO and NO-releasing compounds inhibit ACE activity in a concentration-dependent and competitive way, and that NO physiologically released from the endothelium reduces the conversion of angiotensin I to angiotensin II (12). In vivo, the ACE inhibitor can prevent the coronary vascular and myocardial remodeling induced by long-term inhibition of NO synthesis $(13,14)$. Thus, in the present study we assessed the possible influence of NO on shear stress-induced down-regulation of ACE.

To test this hypothesis, we used a model previously characterized in our laboratory which consists of a rabbit aortic endothelial cell line transfected with $1.3 \mathrm{~kb}$ of rat ACE promoter controlling the luciferase reporter gene (WLuc cells). This approach allowed

Table 1. Angiotensin-I converting enzyme (ACE) and luciferase activity of WLuc cells treated with L-NAME, DEA/NO and SNP for $18 \mathrm{~h}$.

\begin{tabular}{|c|c|}
\hline $\begin{array}{c}\text { ACE activity } \\
\left(\text { (U His-Leu } h^{-1} \mu g \text { DNA }^{-1}\right)\end{array}$ & $\begin{array}{l}\text { Luciferase activity } \\
\text { (U light/.ug DNA) }\end{array}$ \\
\hline
\end{tabular}

L-NAME

$0 \mathrm{mM}$

$0.1 \mathrm{mM}$

$0.5 \mathrm{mM}$

$1.000 \pm 0.090$

$0.993 \pm 0.145$

$0.925 \pm 0.037$

$1 \mathrm{mM}$

$1.272 \pm 0.182 *$

$1.000 \pm 0.065$

$0.907 \pm 0.026$

$1.363 \pm 0.042^{*}$

$1.189 \pm 0.037^{*}$

DEA/NO

$0 \mathrm{mM}$

$0.1 \mathrm{mM}$

$0.5 \mathrm{mM}$

$1.002 \pm 0.074$

$0.957 \pm 0.093$

$1.048 \pm 0.080$

$0.947 \pm 0.099$

$1.000 \pm 0.039$

$1.048 \pm 0.082$

$1.091 \pm 0.062$

$1 \mathrm{mM}$

$1.006 \pm 0.048$

$0.884 \pm 0.0405$

$0.979 \pm 0.060$

$0.986 \pm 0.045$

$1.223 \pm 0.062 *$

$0 \mathrm{mM}$

$0.1 \mathrm{mM}$

$0.5 \mathrm{mM}$

$1 \mathrm{mM}$

Data are reported as the mean \pm SEM of 3 experiments carried out in triplicate. DEA/NO = diethylamine NONOate; L-NAME = NG-nitro-Larginine methyl ester; SNP = sodium nitroprusside.

${ }^{*} \mathrm{P}<0.05$ compared to no treatment (ANOVA). the simultaneous determination of ACE promoter activity by measuring luciferase activity and ACE activity as the product of the endogenous gene. After each experiment, cells were harvested in borate buffer $(0.5 \mathrm{M}$ boric acid, $1.125 \mathrm{M} \mathrm{NaCl}, 0.1 \%$ Triton $\mathrm{X}$ $100, \mathrm{pH} 8.3$ ) and luciferase and ACE activity were measured in the same sample. The luciferase activity was quantified using the Promega (Madison, WI, USA) luciferase kit according to manufacturer instructions. Briefly, luciferin was added to cellular extracts and production of light was monitored by a luminometer. ACE activity was measured by a modified fluorometric technique in which the lysed cells were incubated with substrate (Hippuryl-His-Leu 8 mM; Sigma, St. Louis, MO, USA) for $3 \mathrm{~h}$ at $37^{\circ} \mathrm{C}$. The amount of His-Leu formed was measured by adding $100 \mu \mathrm{l}$ of $74.5 \mathrm{mM}$ o-phthaldialdehyde and fluorescence was read at $365-\mathrm{nm}$ excitation and 485-nm emission (15). All results were normalized by the amount of DNA present in the sample.

In order to determine whether static basal NO levels interfere with ACE, WLuc cells were treated with the NO synthase inhibitor $\mathrm{N}^{\mathrm{G}}$-nitro-L-arginine methyl ester (L-NAME; Sigma) (Table 1). A time-course response using $0.1,0.5$ and $1 \mathrm{mM}$ L-NAME did not modify ACE or luciferase activity up to $12 \mathrm{~h}$ of treatment (data not shown). After $18 \mathrm{~h}$ of incubation with 0.5 or $1 \mathrm{mM}$ L-NAME, there was an increase in luciferase activity, whereas the 1-mM concentration also led to increased ACE activity. To further assess whether NO influences ACE under static conditions, two spontaneous NO donors were administered (Table 1). Treatment of WLuc cells with 0.1, 0.5 and $1 \mathrm{mM}$ diethylamine NONOate (DEA/ NO; OXIS International, Inc., Portland, OR, USA) and sodium nitroprusside (Sigma) did not change ACE activity. The 1-mM concentration of DEA/NO for $18 \mathrm{~h}$ led to an increase in luciferase activity. The effect of NO donors on the cell culture media was confirmed by measuring by chemilumines- 
cence the amount of nitrite and nitrate, which increased by 8 -fold (data not shown).

These results indicated that NO may have an inhibitory influence on basal ACE activity levels and expression in endothelial cells. Furthermore, this influence appears to be mediated at least in part at the transcriptional level and the 1.3-kb ACE promoter fragment studied contains some of the regulatory elements involved.

As reported previosly (11), shear stress of $15 \mathrm{dyn} / \mathrm{cm}^{2}$ for $18 \mathrm{~h}$ decreases ACE activity and expression and increases $\mathrm{NO}$ production. To determine if the decrease in ACE activity induced by shear stress is mediated by NO, WLuc cells were treated with $\mathrm{L}$ NAME $1 \mathrm{~h}$ before starting the shear stress stimulus and for the remaining period of the experiment. Pretreatment with L-NAME was performed to guarantee that NO synthase was inhibited when the shear stress stimulus was started. Shear stress was produced using a cone plate system as described by Malek and Izumo (3). This system consists of a cone with a $0.5^{\circ}$ angle rotating on the cell culture medium. Under these conditions, shear stress is proportional to the angular velocity and can be calculated using the following formula: $\tau=\eta \omega / \alpha$, where $\tau$ is shear stress, $\eta$ is medium viscosity, $\omega$ is angular velocity, and $\alpha$ is the cone angle. As shown in Table 1, $0.1 \mathrm{mM}$ L-NAME did not modify basal ACE or luciferase activity, whereas $1 \mathrm{mM}$ L-NAME led to their increase by $27 \%$. When cells were subjected to shear stress in the presence of L-NAME (0.1 and $1 \mathrm{mM}$ ), the decrease in ACE activity was of the same magnitude as in the absence of the NO synthase inhibitor (Figure 1). The amount of decrease between the static and shear condition was the same among all groups studied $\left(\Delta_{(0 \mathrm{mM})}=0.26 \pm 0.055\right.$, $\Delta_{(0.1 \mathrm{mM})}=0.21 \pm 0.22, \Delta_{(1 \mathrm{mM})}=0.36 \pm 0.13$; $\mathrm{P}=0.7862$ ). These results are consistent with the idea that $\mathrm{NO}$ does not participate in shear stress-induced ACE down-regulation.

The mechanotransduction of shear stress has not been well characterized. There is evidence that shear forces can activate potassium ion channels and the pathways of $\mathrm{G}$ proteins and mitogen-activated protein kinase (MAPK) (16). It was also demonstrated that signaling of the extracellular signal-regulated kinase (17) and c-Jun N-terminal kinase $(18,19)$ pathways are activated by shear stress. The interplay and/or synergism among different pathways remains elusive. These transduction cascades can be activated by growth factor receptors or mechanical stimuli (for example, stretch and shear stress). When endothelial cells are subjected to shear stress, the cytoskeletal network is rearranged and the intracellular tension is redistributed. During this process, the integrins are involved and the kinases that are present in the focal adhesion can be activated and trigger the MAPK pathway. It is known that shear stress also regulates the production of growth factors such as PDGF and FGF that also activate MAPK signaling. The autocrine/paracrine release of these hormones can also be responsible for the activa-

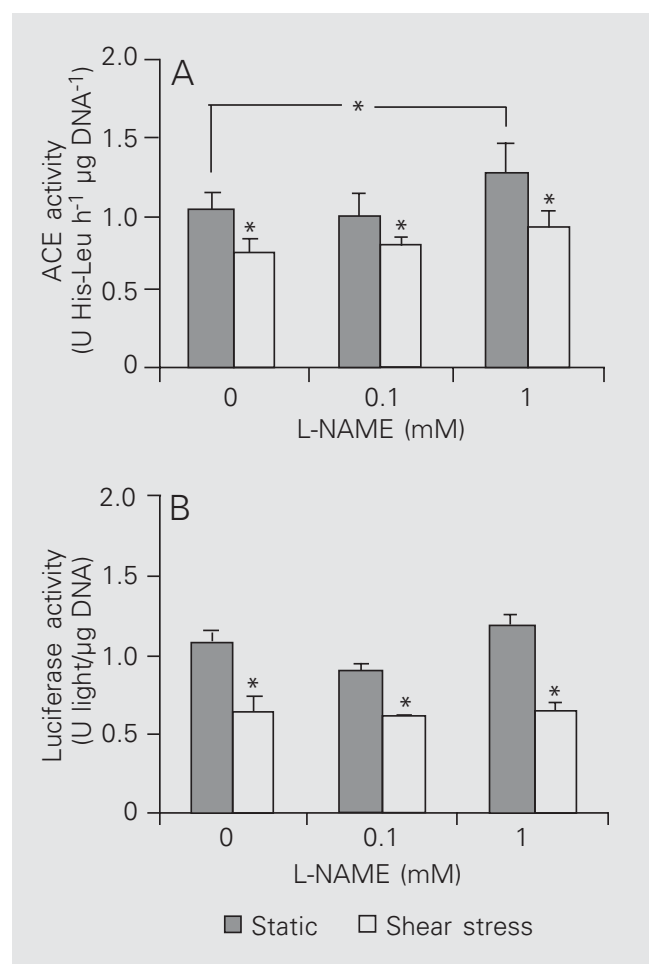

Figure 1. Angiotensin-I converting enzyme (ACE) (A) and luciferase (B) activity in WLuc cells under static conditions and subjected to shear stress of $15 \mathrm{dyn} /$ $\mathrm{cm}^{2}$ for $18 \mathrm{~h}$. The cells were treated with $\mathrm{NG}^{\mathrm{G}}$-nitro-L-arginine methyl ester (L-NAME) $1 \mathrm{~h}$ before the beginning of shear stress and for the remaining period of the experiment. Each bar indicates the mean \pm SEM of 8 experiments. The results were normalized to static cells with no treatment. ${ }^{*} \mathrm{P}<0.05 \mathrm{com}$ pared to static control (ANOVA). 
tion of MAPK by shear stress. The potential sensor for the shear stress stimulus remains unknown, with a variety of reports demonstrating the activation of different transduction cascades (ion channels, G protein, and MAPK). While NO is a likely mediator inter- acting with such signaling pathways under several conditions, our results provide evidence that $\mathrm{NO}$ can influence basal ACE levels but may not influence the shear stressinduced ACE down-regulation.

\section{References}

1. Ziegler T, Silacci P, Harrison VJ \& Hayoz D (1998). Nitric oxide synthase expression in endothelial cells exposed to mechanical forces. Hypertension, 32: 351-355.

2. Frangos JA, Eskin SG, Mclntire LV \& Ives CL (1985). Flow effects on prostacyclin production by cultured human endothelial cells. Science, 227: 1477-1479.

3. Malek AM \& Izumo S (1992). Physiological fluid shear stress causes down-regulation of endothelin-1 mRNA in bovine aortic endothelium. American Journal of Physiology, 263: C389-C396.

4. Hsieh HJ, Li NO \& Frangos JA (1992). Shear-induced plateletderived growth factor gene expression in human endothelial cells is mediated by protein kinase C. Journal of Cellular Physiology, 150: 552-558.

5. Malek AM, Gibbons GH, Dzau VJ \& Izumo S (1993). Fluid shear stress differentially modulates expression of genes encoding basic fibroblast growth factor and platelet-derived growth factor B chain in vascular endothelium. Journal of Clinical Investigation, 92: 20132021.

6. Kuchan MJ \& Frangos JA (1994). Role of calcium and calmodulin in flow-induced nitric oxide production in endothelial cells. American Journal of Physiology, 266: C628-C636.

7. Frangos JA, Huang TY \& Clark CB (1996). Steady shear and step changes in shear stimulate endothelium via independent mechanisms - superposition of transient and sustained nitric oxide production. Biochemical and Biophysical Research Communications, 224: 660-665.

8. Tsao PS, Wang BY, Buitrago R, Shyy YJ \& Cooke JP (1997). Nitric oxide regulates monocyte chemotactic protein-1. Circulation, 96: 934-940.

9. Khan BV, Harrison DG, Olbrych MT \& Alexander RW (1996). Nitric oxide regulates vascular cell adhesion molecule 1 gene expression and redox-sensitive transcriptional events in human vascular endothelial cells. Proceedings of the National Academy of Sciencies, USA, 93: 9114-9119.

10. Bao X, Lu C \& Frangos JA (1999). Temporal gradient in shear but not steady shear stress induces PDGF-A and MCP-1 expression in endothelial cells: role of NO, NFk-B and egr-1. Arteriosclerosis, Thrombosis, and Vascular Biology, 19: 996-1003.

11. Rieder MJ, Carmona R, Krieger JE, Pritchard Jr KA \& Greene AS (1997). Suppression of angiotensin-converting enzyme expression and activity by shear stress. Circulation Research, 80: 312-319.

12. Ackermann A, Fernandez-Alfonso MS, Sanchez de Rojas R, Ortega T, Paul M \& Gonzalez C (1998). Modulation of angiotensin-converting enzyme by nitric oxide. British Journal of Pharmacology, 124 : 291-298.

13. Sanada S, Kitakaze M, Node K et al. (2001). Differential subcellular actions of ACE inhibitors and AT(1) receptor antagonists on cardiac remodeling induced by chronic inhibition of $\mathrm{NO}$ synthesis in rats. Hypertension, 38: 404-411.

14. Takemoto M, Egashira K, Tomita H, Usui M, Okamoto H, Kitabatake A, Shimokawa H, Sueishi K \& Takeshita A (1997). Chronic angiotensin-converting enzyme inhibition and angiotensin II type 1 receptor blockade: effects on cardiovascular remodeling in rats induced by the long-term blockade of nitric oxide synthesis. Hypertension, 30: 1621-1627

15. Oliveira EM, Santos RAS \& Krieger JE (2000). Standardization of a fluorimetric assay for the determination of tissue angiotensin-converting enzyme activity in rats. Brazilian Journal of Medical and Biological Research, 33: 755-764.

16. Davies PF (1989). How do vascular endothelial cells respond to flow? News in Physiological Sciences, 4: 22-25.

17. Tseng $H$, Peterson TE \& Berck BC (1995). Fluid shear stress stimulates mitogen-activated protein kinase in endothelial cells. Circulation Research, 77: 869-878.

18. Li YS, Shyy JY, Li S, Lee J, Su B, Karin M \& Chien S (1996). The RasJNK pathway is involved in shear stress-induced gene expression. Molecular and Cellular Biology, 16: 5947-5954.

19. Go YM, Boo YC, Park H, Maland MC, Patel R, Pritchard Jr KA, Fujio Y, Walsh K, Darley-Usmar V \& Jo H (2001). Protein kinase B/Akt activates c-Jun $\mathrm{NH}$-terminal kinase by increasing $\mathrm{NO}$ production in response to shear stress. Journal of Applied Physiology, 91: 15741581. 